\title{
Antiviral treatment of COVID-19
}

\author{
Serap ȘiMŞEK YAVUZ ${ }^{1, *}$ (), Serhat ÜNAL ${ }^{2}$ (]) \\ ${ }^{1}$ Department of Infectious Disease and Clinical, Microbiology, İstanbul Faculty of Medicine, İstanbul University, İstanbul, Turkey \\ ${ }^{2}$ Department of Infectious Disease, Faculty of Medicine, Hacettepe University, Ankara, Turkey
}

\begin{abstract}
Currently, there is not any specific effective antiviral treatment for COVID-19. Although most of the COVID-19 patients have mild or moderate courses, up to 5\%-10\% can have severe, potentially life threatening course, there is an urgent need for effective drugs. Optimized supportive care remains the mainstay of therapy. There have been more than 300 clinical trials going on, various antiviral and immunomodulating agents are in various stages of evaluation for COVID-19 in those trials and some of them will be published in the next couple of months. Despite the urgent need to find an effective antiviral treatment for COVID-19 through randomized controlled studies, certain agents are being used all over the world based on either in-vitro or extrapolated evidence or observational studies. The most frequently used agents both in Turkey and all over the world including chloroquine, hydroxychloroquine, lopinavir/ ritonavir, favipiravir and remdesivir will be reviewed here .Nitazoxanide and ivermectin were also included in this review as they have recently been reported to have an activity against SARS-CoV-2 in vitro and are licensed for the treatment of some other human infections.
\end{abstract}

Key words: Covid-19, Sars-CoV-2, antiviral

\section{Introduction}

Currently, there is not any specific effective antiviral treatment for COVID-19. Although most of the COVID-19 patients have mild or moderate course, up to $5-10 \%$ can have severe, potentially life threatening course, there is an urgent need for effective drugs [1]. Optimized supportive care remains the mainstay of therapy. As new data regarding clinical characteristics, treatment options, and outcomes for COVID-19 emerges approximately every hour, physicians who are in the care of patients should keep themselves up to date on this issue. There have been more than 300 clinical trials going on, and some of them will be published in the next couple of months. The WHO is launching "Solidarity" clinical trial for COVID-19 treatments to further evaluate remdesivir, hydroxychloroquine/chloroquine, and lopinavir-ritonavir with and without interferon beta ${ }^{1}$. Various other antiviral and immunomodulating agents are in various stages of evaluation for COVID-19. A registry of international clinical trials can be found on the WHO website and at ClinicalTrials.gov.

At the moment, it is strongly recommended that patients be recruited into ongoing trials, which would provide much-needed evidence on the efficacy and safety of various therapies for COVID-19, given that we could not determine whether the benefits outweigh harms for most treatments $[2]^{2}$.

Unless used in the context of randomized clinical trials, antivirals will not be proved to be efficacious or safe for the treatment of COVID-19. In the 2014 Ebola outbreak, close to 30, 000 individuals developed Ebola viral disease, and numerous therapies were tested against this virus, including chloroquine, hydroxychloroquine, favipiravir, brincidofovir, monoclonal antibodies, antisense RNA, and convalescent plasma, among many others. With such a large number of therapeutic interventions given to affected

\footnotetext{
${ }^{1}$ World Health Organization (2020). "Solidarity" clinical trial for COVID-19 treatments [online]. Website https://www.who.int/ emergencies/diseases/novel-coronavirus-2019/global-research-on-novel-coronavirus-2019-ncov/solidarity-clinical-trial-for-covid-19treatments [accessed 12 April 2020].

${ }^{2}$ Bhimraj A, Morgan RL, Shumaker AH, Lavergne V, Baden5 L et al. Infectious DiseasesSociety of America Guidelines on the Treatment and Management of Patients with COVID-19 Infection [online]. Website https://www.idsociety.org/globalassets/idsa/ practice-guidelines/covid-19/treatment/idsa-covid-19-gl-tx-and-mgmt-4-11-20-1058-am-edt.pdf [accessed 12 April 2020].
}

*Correspondence: serapsimsekyavuz@gmail.com 
patients, the goal was to determine which was efficacious against Ebola. Ultimately, none proved to be efficacious or safe, just because of virtually all studies were singlegroup interventions without concurrent controls, which led to no definitive conclusion related to efficacy or safety. This tragedy of not discovering new therapies during an outbreak should not be repeated [3].

The vast majority of patients with COVID-19 will do fine without any therapy, so in most cases, there's no need for antiviral therapy. However, waiting until patients are severely ill before initiating therapy could cause us to miss an early treatment window, during which the disease course is more modifiable. It is known that antiviral therapy is most likely to provide benefit when initiated earlier during the course of the disease both in influenza [4] and in SARS [5]. Predictors of adverse outcome might be useful in predicting who will do poorly and thus who might benefit most from early antiviral therapy ${ }^{3}$. It is logical to start antiviral treatment as soon as possible also for COVID-19 patients especially in the case of the presence of predictors of adverse outcomes.

Combined usage of antiviral drugs for COVID-19 patients should be considered in the light of current knowledge and case by case; adverse drug reactions and drug-drug interactions should always be regarded.

Despite the urgent need to find an effective antiviral treatment for COVID-19 through randomized controlled studies, certain agents are being used all over the world based on either in vitro or extrapolated evidence or observational studies. The most frequently used agents both in Turkey and all over the world including chloroquine, hydroxychloroquine, lopinavir/ritonavir, favipiravir and remdesivir will be reviewed here ${ }^{4567}$. Nitazoxanide and ivermectin were also included in this review as they have recently been reported to have an activity against SARS-CoV-2 in vitro and are licensed for the treatment of some other human infections. Mechanisms of actions of these drugs were shown in Table.

\subsection{Hydroxychloroquine and Chloroquine}

Chloroquine (CQ) and hydroxychloroquine (HCQ) are aminoquinolines, which have been used to treat malaria and autoimmune diseases for over 50 years. Besides their antimalarial effects, these two drugs possess immunomodulatory effects allowing them to use for the treatment of autoimmune conditions such as systemic lupus erythematosus and rheumatoid arthritis. Hydroxychloroquine and chloroquine can inhibit certain cellular functions and molecular pathways involved in immune activation [Inhibition of MHC class II expression, antigen presentation and immune activation (reducing CD154 expression by $\mathrm{T}$ cells); inhibition of production of various proinflammatory cytokines, such as IL-1, IFNa and TNF, which can protect against cytokine-mediated cartilage resorption; interference with Toll-like receptor 7 (TLR7) and TLR9 signaling pathways; interference with cyclic GMP-AMP (cGAMP) synthase (cGAS) activity] partly by accumulating in lysosomes and auto phagosomes of phagocytic cells and changing local $\mathrm{pH}$ concentrations [6]. Chloroquine analogs are weak diprotic bases (can accept more two protons) and they can penetrate and concentrate within acidic organelles such as endosomes and lysosomes which leads to elevated intra-vesicular $\mathrm{pH}$ resulting in prevention of endosome trafficking and prevents viral fusion into the cell. This mechanism has translated to the potential role of these drugs in the treatment of COVID-19. Additionally, studies also revealed that these drugs interfers with the glycosylation of ACE-2 receptor which prevents SARS-CoV-2 receptor binding and subsequent infection. Recent in vitro studies reported CQ and HCQ effective against SARS-CoV-2 at a multiplicity of infection (MOI) of 0.01 with a $50 \%$ effective concentration (EC50) of $2.71 \mu \mathrm{M}$ and $4.51 \mu \mathrm{M}$ in Vero E6 cells, respectively. At all MOIs (0.01, 0.02, 0.2, and 0.8$)$, EC50 for CQ $(2.71,3.81,7.14$, and $7.36 \mu \mathrm{M})$ was lower than that of HCQ $(4.51,4.06,17.31$, and $12.96 \mu \mathrm{M})$ [7-9]. In another in vitro analysis, HCQ was found to be more potent than CQ at inhibiting SARS-CoV-2 and HCQ sulfate $400 \mathrm{mg}$ given twice daily for 1 day, followed by 200

\footnotetext{
${ }^{3}$ Internet Book of Critical Care (IBCC) (2020). COVID-19 [online]. Website https://emcrit.org/ibcc/COVID19/\#background_on_ antiviral_therapy [accessed 12 April 2020].

${ }^{4}$ T.C. Sağlık Bakanlığı Halk Sağlığı Genel Müdürlüğü (2020). COVID-19 (SARS-CoV-2 Enfeksiyonu Rehberi, Bilim Kurulu Çalışması [online]. Website https://covid19bilgi.saglik.gov.tr/depo/rehberler/COVID-19_Rehberi.pdf [accessed 12 April 2020].

${ }^{5}$ Institute of Tropical Medicine, Universiteit Antwerten, CHU Saint-Pierre, Sciensano, AFMPS Fagg (2020). Interim clinical guidance for adults with suspected or confirmed covid-19 in Belgium, Version 7 [online]. Website https://epidemio.wiv-isp.be/ID/Documents/ Covid19/COVID-19_InterimGuidelines_Treatment_ENG.pdf [accessed 12 April 2020].

${ }^{6}$ World Health Organization (2020). Report of the WHO-China joint mission on coronavirus disease 2019 (COVID-19) [online]. Website https://www.who.int/docs/default-source/coronaviruse/who-china-joint-mission-on-covid-19-final-report.pdf [accessed 12 April 2020].
}

${ }^{7}$ Nebraska Medicine (2020). COVID-19 Antiviral and pharmacotherapy recommendations [online]. Website https://www.nebraskamed. com/sites/default/files/documents/covid-19/covid19-antiviral-pharmacotherapy-recommendations.pdf [accessed 12 April 2020]. 
Table. Antivirals investigated for the treatment of COVID-19 in clinical trials or in vitro studies.

\begin{tabular}{|c|c|c|c|}
\hline Group & Drugs & Mechanism of action & Dosing \\
\hline \multirow{2}{*}{$\begin{array}{l}\text { Inhibitors of viral RNA } \\
\text { polymerase / RNA synthesis }\end{array}$} & Remdesivir (GS-5734) & $\begin{array}{l}\text { Adenosine nucleotide analogue, prodrug, } \\
\text { RdRp inhibitor }\end{array}$ & $\begin{array}{l}\text { Day 1: } 200 \mathrm{mg}, \mathrm{IV} \\
\text { Day 2-5 (or } 10 \text { ): } 100 \mathrm{mg} / \text { day, } \\
\text { IV }\end{array}$ \\
\hline & Favipiravir & $\begin{array}{l}\text { Guanosinenucleotid analogue, prodrug, } \\
\text { RdRp inhibitor }\end{array}$ & $\begin{array}{l}\text { Day 1: } 2 \text { X1600 mg } \\
\text { Day 2-7 (or 10): } 2 \times 600 \mathrm{mg} / \\
\text { day }\end{array}$ \\
\hline $\begin{array}{l}\text { Inhibitors of viral protein } \\
\text { synthesis }\end{array}$ & Lopinavir/ritonavir & Protease inhibitor & $\begin{array}{l}\text { Day } 1-10(\text { or } 14) \text { : } \\
400 \mathrm{mg} / 100 \mathrm{mg} \times 2 / \text { day, orally }\end{array}$ \\
\hline \multirow{2}{*}{ Viral entry inhibitors } & Hydroxychloroquine & \multirow{2}{*}{$\begin{array}{l}\text { Increasing endosomal } \mathrm{pH} \text { required for virus/ } \\
\text { cell fusion, as well as interfering with the } \\
\text { glycosylation of cellular receptors of SARS- } \\
\text { CoV (ACE-2) }\end{array}$} & $\begin{array}{l}\text { Day 1-5: } 2 \times 200 \mathrm{mg} / \text { day, } \\
\text { orally }\end{array}$ \\
\hline & Chloroquine & & $\begin{array}{l}\text { Day } 1-5 \text { (or } 10): 2 \times 500 \mathrm{mg} / \\
\text { day, orally }\end{array}$ \\
\hline \multirow[t]{2}{*}{ Imunomodulators } & Nitazoxanide & $\begin{array}{l}\text { Interference with host-regulated pathways } \\
\text { involved in viral replication, amplifying } \\
\text { cytoplasmic RNA sensing and type I IFN } \\
\text { pathways }\end{array}$ & \\
\hline & Ivermectin & $\begin{array}{l}\text { Inhibition nuclear import of host and viral } \\
\text { proteins through inhibition of importin } 1 \\
\text { heterodimer }\end{array}$ & \\
\hline
\end{tabular}

Modified from “Hoffmann C. Treatment. In: Kamps BS, Hoffmann C, eds. Covid Reference, Edition 2020-2. Website www.covidreference. com"

mg twice daily for 4 more days is recommended to treat SARS-CoV-2 infection $[10,11]$.

The use of CQ or HCQ is included in COVID-19 treatment guidelines all over the world but data supporting this is quite scare. An early report from China suggested that chloroquine usage was associated with reduced progression of the disease and decreased duration of symptoms [12]. However, primary data supporting these claims have not been published.

In a prospective randomized trial of 30 adults with COVID-19 in China, 15 patients treated with $400 \mathrm{mg}$ HCQ + conventional treatment were compared with 15 patients treated with conventional treatment only. The proportion of patients with nasopharyngeal viral clearance at day 7 , mean viral clearance time, temperature normalization and progression rate in $\mathrm{CT}$

were not found to be different between the groups, and one patient in the HCQ group progressed to severe disease [13] .

In another randomized trial of 62 patients with mild COVID-19 pneumonia without hypoxia reported that the body temperature recovery time and the cough remission time were significantly shortened in the HCQ treatment group. Additionally, HCQ treatment group experienced more improvement of pneumonia symptoms $(80.6 \%, 25$ of 31) compared with the control group (54.8\%, 17 of 31). Notably, all 4 patients progressed to severe illness occurred in the control group. However, there were 2 patients with mild adverse reactions in the HCQ treatment group. But, the trial has not been published in a peer-reviewed journal, and there are concerns about concomitant cotherapies, baseline differences between the groups, and lack of blinding or placebo control ${ }^{8}$.

Other published clinical data on either of these agents are limited and have methodologic problems. In an openlabel case-control study of 36 adults with COVID-19, use of HCQ (200 mg three times per day for 10 days) was associated with a higher rate of undetectable SARS-CoV-2 RNA on nasopharyngeal specimens at day 6 compared with no specific treatment (70 versus $12.5 \%$, $(\mathrm{P}<0.001)$. While the combination of HCQ with azithromycin resulted in $100 \%$ viral clearance in 6 patients, HCQ alone resulted in $\% 57$ clearance in 14 patients $(\mathrm{P}<0.001)$ [14].

\footnotetext{
${ }^{8}$ Chen Z, Hu J, Zhang Z, Jiang S, Han S et al. (2020). Efficacy of hydrochlroquine in patients with COVID-19: Results of a randomized trial [online]. Website https://www.medrxiv.org/content/10.1101/2020.03.22.20040758v2 [accessed 12 April 2020].
} 
The same group also published the results of 80 COVID-19 patients receiving a combination of HCQ and azithromycin. They noted clinical improvement in all but one 86-year-old patient who died and one 74-yearold patient still in the intensive care unit. A rapid fall of nasopharyngeal viral load tested by qPCR was noted, with $83 \%$ negative at day 7 , and $93 \%$ on day 8 . Virus cultures from patient's respiratory samples were negative in $97.5 \%$ patients on day5 [15]. Both of these studies have substantial methodological problems that cast doubt on the conclusions $[2]^{9}$.

Unfortunately, these studies have resulted in the massive adoption of the regimen by clinicians worldwide. There are also increasing concerns about the safety of these drugs: both medications have been independently shown to increase the risk for QT interval prolongation, druginduced torsade's de pointes, and drug induced-sudden cardiac death $[16]^{10}$.

In a preliminary safety result of a randomized, doubleblinded, phase IIb clinical trial (CloroCovid-19 Study) aiming to assess safety and efficacy of two different CQ dosages as adjunctive therapy of hospitalized patients with SARS-CoV-2, the high dose CQ arm presented more QTc > $500 \mathrm{~ms}(25 \%)$, and a trend toward higher lethality (17\%) than the lower dosage in the first recruited 81 patients. Preliminary findings suggest that the higher CQ dosage (10-day regimen) should not be recommended for COVID-19 treatment because of its potential safety hazards. As a result, investigators prematurely halted patient recruitment to this arm [17].

In another recent study from USA, researchers reported the change in the QT interval in 84 adult patients with SARS-CoV-2 infection treated with HCQ/ Azithromycin combination. They reported that QTc prolonged maximally from baseline between days 3 and 4, in $30 \%$ of patients QTc increased by greater than $40 \mathrm{~ms}$ and in $11 \%$ of patients QTc increased to $>500 \mathrm{~ms}$, representing high-risk group for arrhythmia. The development of acute renal failure but not baseline QTc was a strong predictor of extreme QTc prolongation ${ }^{11}$.

Finally, a total of 54 serious cardiac events, 7 sudden cardiac arrests (4 deaths), 37 prolonged QT and 10 arytmia + syncope have been reported to French National Pharmacovigilance Agency since the 27th of March $2020^{12}$.

CQ and HCQ have also been suggested as a candidate for antiviral prophylaxis against the current COVID-19 pandemic because of its demonstrated mechanisms of action of preventing viral entry and fusion, evidence of in vitro efficacy at a clinically achievable dose and high tissue concentration as well as preliminary clinical evidence of efficacy as a treatment. But there is also insufficient data to support this suggestion and these agents should not be used as prophylactic agents for SARS-CoV-2 except in the context of a clinical trial ${ }^{13}$.

There are insufficient data thus far to know whether HCQ or CQ has a role either in the treatment or in the prophylaxis of COVID-19. Beside antimalarial drugs can cause ventricular arrhythmias, QT prolongation, and other cardiac toxicity, which may pose a particular risk to critically ill persons. Given these serious potential adverse effects, the hasty and inappropriate interpretation of the literature by public leaders has the potential to do serious harm. For these reasons, it is strongly recommended that patients should be referred to a clinical trial whenever possible. Ongoing trials for HCQ are actively recruiting with hopes to further delineate its role in the treatment and prophylaxis of COVID-19 [11].

\subsection{Favipiravir}

Favipiravir (T-705; 6-fluoro-3-hydroxy-2pyrazinecarboxamide) is an antiviral agent that selectively and potently inhibits the RNA-dependent RNA polymerase (RdRp) of RNA viruses. Favipiravir undergoes an intracellular phosphoribosylation to be an active form, favipiravir ribofuranosyl-5B-triphosphate (favipiravirRTP), which is recognized as a substrate by RdRp, and inhibits the RNA polymerase activity. Since the catalytic

\footnotetext{
${ }^{9}$ International Society of Antimicrobial Chemotherapy (2020). Statement on IJAA paper[online]. Website https://www.isac.world/ news-and-publications/official-isac-statement [accessed 12 April 2020].
}

${ }^{10}$ Chang R, Sun WZ (2020). Repositioning chloroquine as an ideal antiviral prophylaxis against COVID-19-time is now [online]. Website https://www.preprints.org/manuscript/202003.0279/v1 . [accessed 12 April 2020].

${ }^{11}$ Borba MGS, De Almeida Val F, Sampaio VS, Araújo Alexandre MA, Melo GC et al. (2020). Chloroquine diphosphate in two different dosages as adjunctive therapy ofhospitalized patients with severe respiratory syndrome in the context of coronavirus (SARS-CoV-2) infection: preliminary safety results of a randomized, double-blinded, phase IIb clinical trial (CloroCovid-19 Study) [online]. Website https://www.medrxiv.org/content/10.1101/2020.04.07.20056424v2 [accessed 12 April 2020].

${ }^{12}$ Chorin E, Dai M, Shulman E, Wadhwani L, Cohen RB et al. (2020). The QT interval in patients with SARS-CoV-2 infection treated with hydroxychloroquine/azithromycin [online]. Website https://www.medrxiv.org/content/10.1101/2020.04.02.20047050v1 [accessed 12 April 2020].

13 Le Monde (2020). Covid-19-les-effets-indesirables-graves-s-accumulent-sur-l-hydroxychloroquine [online]. Website https://www.lemonde.fr/planete/article/2020/04/09/covid-19-les-effets-indesirables-graves-s-accumulent-sur-1hydroxychloroquine_6036139_3244.html [accessed 12 April 2020]. 
domain of RdRp is conserved among various types of RNA viruses, this mechanism of action may underpins a broader spectrum of antiviral activities of favipiravir. Favipiravir-RTP inhibits RdRp of the influenza virus with an IC50 of $0.022 \mu \mathrm{g} / \mathrm{mL}$, but does not affect the human DNA polymerases $\alpha, \beta, \gamma$ subunits at up to $100 \mu \mathrm{g} / \mathrm{mL}$. In addition to the inhibition of influenza virus, favipiravir shows inhibitory effects on a wide range of RNA viruses, such as arena-, bunya-, flavi- and filoviruses causing hemorrhagic fevers $[18,19]$. It has been shown to be effective in the treatment of influenza and in some extent Ebola virus disease [19-21]. Genome sequencing of the 2019-nCoV identified the virus as a single-stranded RNA beta-coronavirus with the RdRp gene similar to those of SARS-CoV and MERS-CoV. Therefore, favipiravir is considered as one of the potential candidates for COVID-19, though confirmed in vitro and preclinical animal studies are not available yet. In an in-vitro study, SARS-CoV-2 was inhibited by favipiravir in Vero E6 cells with an EC50 of $61.88 \mu \mathrm{Mol}$ [14]. But in another study favipiravir showed no apparent antiviral effect against the SARS-CoV-2 virus in vitro at concentrations under 100 $\mu \mathrm{ML}$ [22].

In an open-label, controlled study of 80 patients with laboratory-confirmed COVID-19, 35 patients who received oral favipravir plus interferon (IFN)- $\alpha$ by aerosol inhalation were compared with 45 patients who received lopinavir/ritonavir plus IFN- $\alpha$ by aerosol inhalation. All baseline characteristics were comparable between the two arms. A shorter viral clearance time was found for the favipiravir arm versus the control arm [median (interquartile range, IQR), 4 (2.5-9) d versus 11 (8-13) $\mathrm{d}, \mathrm{P}<0.001]$. The favipiravir arm also showed significant improvement in chest imaging compared with the control arm, with an improvement rate of $91.43 \%$ versus $62.22 \%$ $(\mathrm{P}=0.004)$. After adjustment for potential confounders, the favipiravir arm also showed a significantly higher improvement rate in chest imaging. Multivariable Cox regression showed that favipiravir was independently associated with faster viral clearance [23]. But this article has been temporarily removed by the publisher and the reason for the removal of the article has not been specified yet and rising the suspicion on the results of the study.

In a randomized clinical trial ${ }^{14} 120$ patients who were assigned to the favipiravir group compared with 120 arbidol treated patients. In patients with mild-moderate COVID-19, 7 day's clinical recovery rate was $55.86 \%$ in the arbidol group and $71.43 \%$ in the favipiravir group $(\mathrm{P}=$ 0.0199). For mild-moderate COVID-19 patients the time of fever reduction and cough relief in the favipiravir group was significantly shorter than that in the arbidol group (both $\mathrm{P}<0.001$ ), no difference was observed of auxiliary oxygen therapy or noninvasive mechanical ventilation rate (both $\mathrm{P}>0.05$ ). The most possible adverse events were abnormal liver function tests, psychiatric symptom reactions, digestive tract reactions and raised serum uric acid [3 (2.50\%) in arbidol group vs. 16 (13.79\%) in favipiravir group, $\mathrm{P}<0.0001]$. These trials have not been published in a peer-reviewed journal, and there are concerns about concomitant co-therapies, baseline differences between the groups, and lack of blinding or placebo control.

At the moment current knowledge is not enough to recommend favipiravir for the treatment of COVID-19 and additional studies are needed. There are several RCT going on in China.

\subsection{Remdesivir}

Remdesivir is a novel antiviral drug developed by Gilead Sciences, originally for the treatment of Ebola virus disease and Marburg virus infections. Remdesivir is a prodrug of a nucleotide analog that is intracellularly metabolized to an analog of adenosine triphosphate that inhibits viral RNA polymerases. Remdesivir has broadspectrum activity against members of several virus families, including filoviruses (e.g., Ebola) and coronaviruses [e.g., SARS$\mathrm{CoV}$ and Middle East respiratory syndrome coronavirus (MERSCoV)] and has shown prophylactic and therapeutic efficacy in nonclinical models of these coronaviruses. In vitro testing has also shown that remdesivir has activity against SARS-CoV-2 with an EC50 value of $1.76 \mu \mathrm{M}$ in Vero E6 cells suggesting its working concentration is likely to be achieved in nonhuman primate models [8]. Treatment with intravenous remdesivir showed significant improvement for the first COVID-19 case in US [24] and then a trial has been initiated quickly to assess the efficacy and safety of remdesivir in patients hospitalized with 2019-nCoV infection. In a cohort of patients hospitalized for severe Covid-19 who were treated with compassionate use remdesivir, clinical improvement was observed in 36 of 53 patients (68\%) [25]. As there was no placebo or active comparator in this study, it is hard to draw any concrete conclusions and measurement of efficacy will require results of ongoing randomized, placebo-controlled trials of remdesivir therapy. There are 4 clinical trials currently enrolling patients in the United States and, two additional trials recruiting only in China have been registered on ClinicalTrials.gov, NCT04257656 (severe disease) and NCT04252664 (mild-moderate disease) [2].

\subsection{Lopinavir/ritonavir( LPV/r)}

Lopinavir is a protease inhibitor used to treat HIV infection, with ritonavir as a booster. Protease is a key

\footnotetext{
${ }^{14}$ Chen C, Huang J, Cheng Z, Zhang Y, Cheng Z et al. (2020). Favipiravir versus arbidol for COVID-19: a randomized clinical trial [online]. Website https://www.medrxiv.org/content/medrxiv/early/2020/04/08/2020.03.17.20037432.full.pdf [accessed 12 April 2020].
} 
enzyme in coronavirus polyprotein processing and lopinavir and/or ritonavir has anti coronavirus activity in vitro. Most in vitro studies have shown that SARS$\mathrm{CoV}$ could be inhibited by lopinavir and that the EC50 of lopinavir is acceptable. Lopinavir showed an antiviral effect against SARS-CoV-2 virus in Vero E6 cells with the estimated EC50 at $26.63 \mu \mathrm{M}$ [26].

Furthermore, two retrospective matched cohort studies of SARS patients revealed that LPV/r plays an essential role in the clinical outcome, especially in the early stage. In a study from Hong-Kong, compared with ribavirin alone, patients treated with lopinavir/ritonavir plus ribavirin had a lower risk of acute respiratory distress syndrome (ARDS) or death caused by SARS-CoV, $2.4 \%$ vs. $28.8 \%, \mathrm{P}=0.001$ ) at day 21 after the onset of symptoms [27].

$\mathrm{LPV} / \mathrm{r}$ treatment alone or in combination with interferon had improved clinical outcomes in experiments involving common marmosets and in some MERS patient [28].

Postexposure prophylaxis with $\mathrm{LPV} / \mathrm{r}$ was found to be associated with a $40 \%$ decrease in the risk of MERS infection, although the design of the study was raised some concerns [29].

Five patients with COVID-19 in Singapore were treated with LPV/r within 1 to 3 days of desaturation, but evidence of clinical benefit was equivocal. While defervescence occurred within 1 to 3 days of LPV/r initiation, it was unable to prevent progressive disease in 2 patients. A decline in viral load as indicated by the cycle threshold value from nasopharyngeal swabs also appeared similar between those treated and not treated with LPV/r [30].

In another study of of 47 patients with COVID-19; compared with the standard of care (arbidol plus IFN- $\alpha$ inhaler) (SOC) (5 patients), the combination treatment with $\mathrm{LPV} / \mathrm{r}$ plus SOC (42 patients) has resulted in a shorter time (test group: $4.8 \pm 1.94$ days vs. control group: $7.3 \pm$ 1.53 days, $\mathrm{P}=0.0364$ ) to return normal body temperature and to be negative for SARS-CoV-2 test in clinical samples (7.8 \pm 3.09 days vs. $12.0 \pm 0.82$ days, $\mathrm{P}=0.0219$ ) [31].

In another study, 44 patients with mild/moderate COVID-19 were randomly assigned to receive LPV/r (21 patients), arbidol(16 patients) and no antiviral medication as control (7 patients). No statistical differences were found among three groups in the rates of antipyretics, cough alleviation, improvement of chest CT or the deterioration rate of clinical status (all $\mathrm{P}>0.05)$. Overall, 5 (23.8\%) patients in the LPV/r group experienced adverse events during the follow-up period. No apparent adverse events occurred in the arbidol or control group. It was concluded from this study that LPV/r or arbidol monotherapy seems little benefit for improving the clinical outcome of mild/ moderate COVID-19 and LPV/r might lead to more adverse events ${ }^{15}$.

In a randomized trial of 199 patients with severe COVID-19, the addition of LPV/r (400/100 mg) twice daily for 14 days to standard care did not decrease the time to clinical improvement compared with standard care alone [32]. There was a trend towards decreased mortality with LPV/r (19 versus 25 percent), and the numerical difference in mortality was greater among those who were randomized within 12 days of symptom onset, but neither difference was statistically significant. The rate of SARS-CoV-2 decline was similar in the group that received LPV/r and the group that did not. LPV/r was stopped early in 14 percent because of adverse effects. The patients recruited for the study were late in infection and already had considerable tissue damage (as evidenced by compromised lung function and $25 \%$ mortality in the control group). Even highly active antibacterial agents have limited efficacy in advanced bacterial pneumonia [33]. Accelerated clinical recovery ( 16.0 days vs. 17.0 days) and reduced mortality (19.0\% vs. $27.1 \%)$ were observed in a post hoc subgroup of those treated within 12 days after the onset of symptoms, but not in those treated later [48, 49]. Also in another study of 280 COVID-19 patients, time from illness onset to antiviral was found to be a risk factor for severe disease. Patients in the mild group experienced earlier initiation of antiviral treatment (1.19 \pm 0.45 vs. $2.65 \pm 1.06$ days in the severe group, $\mathrm{P}<0.001$ ) [34]. The question of whether earlier $\mathrm{LPV} / \mathrm{r}$ treatment in COVID-19 could have clinical benefit is an important one that requires further studies.

With the available data, it is difficult to assess whether $\mathrm{LPV} / \mathrm{r}$ has a role for the treatment of COVID-19 either as monotherapy or in combination, limited data suggesting no advantage over standard care for SARS-CoV-2. Importantly, it warrants comment that in the recent randomized controlled trial in COVID-19 pneumonia the median time from symptom onset to initiation of therapy was 13 days, and in the SARS CoV-1 experience therapy appeared effective if started early, but not as rescue/salvage.

If utilized, drug interactions must be screened and gastrointestinal toxicities, including diarrhea, nausea, and vomiting, and hepatoxicity require close monitoring, particularly since elevated AST or ALT may exclude patients with COVID-19 from clinical trials.

If $\mathrm{LPV} / \mathrm{r}$ is used, the patient's HIV status should be known and if the patient has HIV, LPV/r should be used as part of a standard combination antiretroviral regimen.

\footnotetext{
${ }^{15}$ Li Y, Xie Z, Lin W, Cai W, Wen C, et al. An exploratory randomized controlled study on the efficacy and safety of lopinavir/ritonavir or arbidol treating adult patients hospitalized with mild/moderate COVID-19 (ELACOI). [online]. Website https://www.medrxiv.org/ content/10.1101/2020.03.19.20038984v2 [accessed 12 April 2020].
} 


\subsection{Nitazoxanide}

Nitazoxanide and its active metabolite, tizoxanide have demonstrated potent in vitro activity against SARS CoV-2 and MERS CoV in Vero E6 cells with an EC50 of $2.12 \mu \mathrm{M}$ and $0.92 \mu \mathrm{M}$, respectively. It also displays broad-spectrum in vitro antiviral activity

against influenza, respiratory syncytial virus, parainfluenza, rotavirus, and norovirus among others in addition to coronaviruses. This broad-spectrum antiviral activity is believed to be due to the fact that the mechanism of action is based on interference with host-regulated pathways involved in viral replication rather than virusspecific pathways [35]. Nitazoxanideupregulates the innate antiviral mechanisms by broadly amplifying cytoplasmic RNA sensing and type I IFN pathways. Nitazoxanide interferes with the viral infection by upregulating the precise host mechanisms that viruses target to bypass host cellular defenses [36]. Due to its broad-spectrum antiviral activity, nitazoxanide is being investigated in clinical trials including randomized controlled ones for the management of influenza and other acute respiratory infections, although results are not encouraging or unavailable yet. Although the in vitro activity of nitazoxanide against SARS-CoV-2 is encouraging, more data are clearly needed to determine its role in the management of COVID-19 [26 ${ }^{16}$.

\subsection{Ivermectin}

Ivermectin is an FDA-approved broad-spectrum antiparasitic agent that in recent years, it has shown to have antiviral activity against a broad range of viruses in vitro. Originally identified as an inhibitor of the interaction between the human immunodeficiency virus-1 (HIV-1) integraseprotein and the importin (IMP) 1 heterodimer responsible for integrase protein nuclear import, ivermectin has since been confirmed to inhibit integrase protein nuclear import and HIV-1 replication. Other actions of ivermectin have been reported, but ivermectin has been shown to inhibit the nuclear import of host and viral proteins. It has been demonstrated to limit infection by some RNA viruses including influenza, dengue and West Nile viruses. Ivermectin has similarly been shown to be effective against the DNA virus pseudorabies virus (PRV) both in vitro and in vivo, with ivermectin treatment shown to increase survival in PRV-infected mice [37]. Efficacy was not observed for ivermectin against Zikavirus in mice, but the authors acknowledged that study limitations justified the reevaluation of ivermectin's anti-Zika virus activity [38]. Finally, ivermectin was the focus of a phase III clinical trial in Thailand in 2014-2017, against dengue virus infection, in which a single daily oral dose was observed to be safe and resulted in a significant reduction in serum levels of viral NS1 protein, but no change in viremia or clinical benefit was observed ${ }^{17}$.

In an in vitro study, ivermectin was found to be an inhibitor of the SARS-CoV-2, with a single addition to Vero-hSLAM cells $2 \mathrm{~h}$ post infection with SARS-CoV-2 able to effect $\sim 5000$-fold reduction in viral RNA at $48 \mathrm{~h}$. Authors hypothesize that this was likely through inhibiting IMPa/ $\beta 1$ - mediated nuclear import of viral proteins (as shown for other RNA viruses) and this inhibition disrupts the immune evasion mechanism of virus [38]. Further in vitro, in vivo and clinical trials are needed to determine its role in the management of COVID-19.

\section{Conflict of interest}

The authors declare no competing interests.

\begin{abstract}
16 Padmanabhan S (2020). Potential dual therapeutic approach against SARS-CoV-2/COVID-19 with Nitazoxanide and Hydroxychloroquine [online].Website https://www.researchgate.net/profile/Srivatsan_Padmanabhan/publication/339941717_ Potential_dual_therapeutic_approach_against_SARS-CoV-2COVID-19_with_Nitazoxanide_and_Hydroxychloroquine/ links/5e825a6aa6fdcc139c173bc2/Potential-dual-therapeutic-approach-against-SARS-CoV-2-COVID-19-with-Nitazoxanide-andHydroxychloroquine.pdf. [accessed 12 April 2020].
\end{abstract}

${ }^{17}$ Yamasmith E, Avirutnan P, Mairiang D, Tanrumluk S, Suputtamongkol Y et al. (2018). Efficacy and safety of ivermectin against dengue infection: a Phase III, randomized, double-blind, placebo-controlled trial [online]. Website http://www.rcpt.org/abstractdb/media/ abstract/CON2018/Best\%20Resident27/BRA_77_Eakkawit.pdf [accessed 12 April 2020].

\title{
References
}

1. Hoffmann C. Treatment. In: Kamps BS, Hoffmann C, eds. Covid Reference, Edition 2020-2. SteinHauser Verlag; Amedeo, Germany; 2020. Website www.covidreference.com [accessed 12 April 2020].

2. McCreary EK, Pogue JM. Coronavirus disease 2019 treatment: a review of early and emerging options. Open Forum Infectious Diseases 2020; 7(4): ofaa105. doi: 10.1093/ofid/ofaa105
3. Kalil AC. Treating COVID-19-Off-Label Drug Use, Compassionate Use, and Randomized Clinical Trials During Pandemics. JAMA 2020. doi: 10.1001/jama.2020.4742

4. Uyeki TM, Bernstein HH, Bradley JS, Englund JA, File TM et al. Clinical practice guidelines by the infectious diseases society of America: 2018 update on diagnosis, treatment, chemoprophylaxis, and institutional outbreak management of seasonal influenzaa. Clinical Infectious Disesases 2019; 68: e1. doi: $10.1093 / \mathrm{cid} /$ ciy 866 
5. Chan KS. Treatment of severe acute respiratory syndrome with lopinavir/ritonavir: a multicentre retrospective matched cohort study. Hong Kong Medical Journal 2003; 9: 399-406.

6. Schrezenmeie E, Dörner T. Mechanisms of action of hydroxychloroquine and chloroquine: implications for rheumatology . Nature Reviews Rheumatology 2020; 16 (3): 155166. doi: $10.1038 / \mathrm{s} 41584-020-0372-\mathrm{x}$

7. Liu J, Cao R, Xu M, Wang X, Zhang H et al. Hydroxychloroquine, a less toxic derivative of chloroquine, is effective in inhibiting SARS-CoV-2 infection in vitro. Cell Discovery 2020. doi: 10.1038/s41421-020-0156-0.15

8. Wang M, Cao R, Zhang L, Yang X, Liu J et al. Remdesivir and chloroquine effectively inhibit the recently emerged novel coronavirus (2019-nCoV) in vitro. Cell Research 2020; 30: 26971. doi: $10.1038 / \mathrm{s} 41422-020-0282-0$

9. Lu CC, MY, Chen, Chang YL. Potential therapeutic agents against COVID-19: What we know so far. Journal of the Chinese Medical Association 2020. doi: 10.1097/JCMA.0000000000000318

10. Yao X, Ye F, Zhang Z,Cui C, Huang B et al. In vitro antiviral activity and projection of optimized dosing design of hydroxychloroquine for the treatment of severe acute respiratory syndrome coronavirus 2 (SARS-CoV-2). Clinical Infectious Diseases 2020; ciaa237. doi: 10.1093/cid/ciaa237

11. Barlow A, Landolf KM, Barlow B, Yeung SYA, Heavner JJ et al. Review of emerging pharmacotherapy for the reatment of coronavirus disease 2019. Pharmacotherapy 2020. doi: 10.1002/ phar.2398

12. Gao J, Tian Z, Yang X. Breakthrough: Chloroquine phosphate has shown apparent efficacy in treatment of COVID-19 associated pneumonia in clinical studies. Bioscience Trends 2020; 14: 72. doi: 10.5582/bst.2020.01047

13. Chen J. A pilot study of hydroxychloroquine in treatment of patients with common coronavirus disease-19 (COVID-19) Journal of Zhejiang University 2020. doi: 10.3785/j.issn.10089292.2020.03.03

14. Gautret P, LagierJG, Parola P, Hoang VT, Meddeb L et al. Hydroxychloroquine and azithromycin as a treatment of COVID-19: results of an open-label non-randomized clinical trial. International Journal of Antimicrobial Agents 2020. doi: 10.1016/j.ijantimicag.2020.105949

15. Gautret P, LagierJG, Parola P, Hoang VT, Meddeb L et al. Clinical and microbiological effect of a combination of hydroxychloroquine and azithromycin in 80 COVID-19 patients with at least a six-day follow up: an observational study. Travel Medicine and Infectious Disease 2020. doi: 10.1016/ j.tmaid.2020.101663

16. Chen CY, Wang FL, Lin CC. Chronic hydroxychloroquine use associated with QT prolongation and refractory ventricular arrhythmia. Clinical Toxicology. 2006; 44: 173-175. doi: 10.1080/15563650500514558

17. Kezerashvili A, Khattak H, Barsky A, Nazari R, Fisher JD. Azithromycin as a cause of QT-interval prolongation and torsade de pointes in the absence of other known precipitating factors. Journal of Interventional Cardiac Electrophysiology 2007; 18: 243-246. doi: 10.1007/s10840-007-9124-y
18. Furuta Y, Komeno T, Nakamura T. Favipiravir (T-705), a broad spectrum inhibitor of viral RNA polymerase. Proceedings of the Japan Academy Series B 2017; 93 (7): 449-463. doi: 10.2183/pjab.93.027

19. Du YX, Chen XP. Favipiravir: pharmacokinetics and concerns about clinical trials for 2019-nCoV infection. Clinical Pharmacology \& Therapeutics 2020. doi: 10.1002/cpt.1844

20. Sissoko D, Laouenan C, Folkesson E, M’Lebing AB, Beavogui $\mathrm{AH}$ et al. Experimental treatment with favipiravir for Ebola virus disease (the JIKI trial): a historically controlled, singlearm proof-of-concept trial in Guinea. PLoS Medicine 2016; 13: e1001967. doi: 10.1371/journal.pmed.1001967

21. Bai CQ, Mu JS, Kargbo D, Song YB, Niu WK et al. Clinical and Virological Characteristics of Ebola Virus Disease Patients Treated With Favipiravir (T-705)-Sierra Leone, 2014. Clinical Infectious Diseases 2016; 63: 1288-1294. doi: 10.1093/cid/ ciw571

22. Choy KT, Wong AYL, Kaewpreedee P, Sia SF, Chen D et al. Remdesivir, lopinavir, emetine, and homoharringtonine inhibit SARS-CoV-2 replication in vitro. Antiviral Research 2020; 178: 104786. doi: 10.1016/j.antiviral.2020.104786.

23. Cai Q, Yang M, Liu D, Chen J, Shu D et al. Experimental treatment with favipiravir for COVID-19: an open-label control study. Engineering 2020. doi: 10.1016/j.eng.2020.03.007

24. Holshue ML, DeBolt C, Lindquist S, Lofy KH, Wiesman J et al. First Case of 2019 Novel Coronavirus in the United States . New England Journal of Medicine 2020; 382: 929-936. doi: 10.1056/NEJMoa2001191

25. Grein J, Ohmagari N, Shin D, Diaz G, Asperges E et al. Compassionate use of remdesivir for patients with severe Covid-19. New England Journal of Medicine 2020. doi: 10.1056/NEJMoa2007016

26. Choy KT, Wong AYL, Kaewpreedee P, Sia SF, Chen D et al. Remdesivir, lopinavir, emetine, and homoharringtonine inhibit SARS-CoV-2 replication in vitro. Antiviral Research 2020; 178: 104786. doi: 10.1016/j.antiviral.2020.104786

27. Chu CM, Cheng VC, Hung IFN,Wong MM, Chan KH et al. Role of lopinavir/ritonavir in the treatment of SARS: Initial virological and clinical findings. Thorax 2004; 59: 252-256. doi: 10.1136/thorax.2003.012658

28. Yao TT, Qian JD, Zhu Y, Wang Y, Wang GQ. A systematic review of lopinavir therapy for SARS coronavirus and MERS coronavirus-A possible reference for coronavirus disease-19 treatment option. Journal of Medical Virology 2020. doi: 10.1002/jmv.25729

29. Park SY, Lee JS, Son JS, Ko JH, Peck KR et al. Post-exposure prophylaxis for Middle East respiratory syndrome in healthcare workers. Journal of Hospital Infection 2019; 101 (1): 42-46. doi: 10.1016/j.jhin.2018.09.005

30. Young BE, Ong SWX, Kalimuddin S, Low JG, Tan SY et al. Epidemiologic Features and Clinical Course of Patients Infected With SARS-CoV-2 in Singapore. JAMA 2020. doi:10.1001/jama.2020.3204 
31. Ye XT, Luo L, Xia SC, Sun QF, Ding JG et al. Clinical efficacy of lopinavir/ritonavir in the treatment of Coronavirus disease 2019. European Review for Medical and Pharmacological Sciences 2020; 24: 3390-3396. doi: 10.26355/eurrev_202003_20706

32. Cao B, Wang Y, Wen D, Liu W, Wanget J et al. A trial of lopinavir-ritonavir in adults hospitalized with severe Covid-19. New England Journal of Medicine 2020. doi: 10.1056/NEJMoa2001282

33. Baden LR, Rubin EJ. Covid-19-The Search for Effective Therapy. New England Journal of Medicine 2020. doi: 10.1056/NEJMoa2001282

34. Wu J, Li W, Shi X, Chen Z, Jiang B et al. Early antiviral treatment contributes to alleviate the severity and improve the prognosis of patients With novel coronavirus Disease (COVID-19). Journal of Internal Medicine 2020. doi: 10.1111/joim.13063
35. Rossignol JF. Nitazoxanide, a new drug candidate forthe treatment of Middle East respiratorysyndrome coronavirus. Journal of Infection and Public Health 2016; 9: 227-230. doi: 10.1016/j.jiph.2016.04.001

36. Jasenosky L D, Cadena C, Mire CE, Borisevich V, Haridas V et al. The FDA-approved oral drug nitazoxanide amplifies host antiviral responses and inhibits Ebola virus. iScience 2019; 19: 1279-1290. doi: 10.1016/j.isci.2019.07.003

37. Caly L, Druce JD, Catton MG, Jans DA, Wagstaff KM. The FDA approved drug ivermectin inhibits the replication of SARS-CoV-2 in vitro. Antiviral Research 2020. doi: 10.1016/j. antiviral.2020.104787

38. Ketkar H, Yang L, Wormser GP, Wang P. Lack of efficacy of ivermectin for prevention of a lethal Zika virus infection in a murine system. Diagnostic Microbiology and Infectious Disease 2019; 95(1): 38-40. doi: 10.1016/j.diagmicrobio.2019.03.012 